Int. J. Electrochem. Sci., 15 (2020) 11070 - 11079

International Journal of

ELECTROCHEMICAL

SCIENCE

www.electrochemsci.org

\title{
Controlled Synthesis of $\mathrm{Zn}_{3}(\mathrm{OH})_{2} \mathrm{~V}_{2} \mathrm{O}_{7} \cdot 2 \mathrm{H}_{2} \mathrm{O}$ with 3D micro/nano-structure via electrochemical method
}

Wenping Jiang ${ }^{1}$, Liheng Zhang ${ }^{2,3}$, Fanqi Min ${ }^{2,3,5}$,Yuanyu Sun ${ }^{1}$, Ying Luo ${ }^{3,4}$, Liqin Yan ${ }^{3,4}$, Guoju Dang ${ }^{3}$, Quansheng Zhang ${ }^{1, *}$, Jingying Xie , $^{2,3,4}$

${ }^{1}$ School of Chemical and Environmental Engineering, Shanghai Institute of Technology, Shanghai 201418, China

${ }^{2}$ School of Chemistry and Chemical Engineering, Harbin Institute of Technology, Harbin 150001, Heilongjiang, China

${ }^{3}$ Shanghai Engineering Center of Power and Energy Storage Battery Systems, Shanghai 200245, China

${ }^{4}$ State Key Laboratory of Space Power-Sources Technology ,Shanghai Institute of Space Power Sources, Shanghai 200245, China

${ }^{5}$ Shanghai Power \& Energy Storage Battery System Engineering Tech. Co. Ltd., Shanghai 200240, China

*E-mail: zhangquansheng@ @it.edu.cn, jyxie@mail.sim.ac.cn

doi: $10.20964 / 2020.11 .74$

Received: 23 July 2020 / Accepted: 11 September 2020 / Published: 30 September 2020

$\mathrm{Zn}_{3}(\mathrm{OH})_{2} \mathrm{~V}_{2} \mathrm{O}_{7} \cdot 2 \mathrm{H}_{2} \mathrm{O}$ is synthesized by an electrochemical method which gives a $3 \mathrm{D}$ micro/nanohierarchical structures consisting of 2D nanosheets that intercrossed each other by self-assembly. The effects of electrolytic parameters (temperature, time, current density, electrolyte concentration) on the powder morphologies are systematically studied and the resulted powders are characterized with XRD, FT-IR, BET, SEM, TEM, etc. The power structure and particle morphology are governed most by the temperature, where higher temperature will lead to better crystallinity and larger particle sizes. The photocatalytic activities of $\mathrm{Zn}_{3}(\mathrm{OH})_{2} \mathrm{~V}_{2} \mathrm{O}_{7} \cdot 2 \mathrm{H}_{2} \mathrm{O}$ prepared at $45^{\circ} \mathrm{C}$ shows highest photocatalytic activity for MB under UV light irradiation.

Keywords: Controlled Synthesis, electrochemical method, Zinc pyrovanadate.

\section{$\underline{\text { FULL TEXT }}$}

(C) 2020 The Authors. Published by ESG (www.electrochemsci.org). This article is an open access article distributed under the terms and conditions of the Creative Commons Attribution license (http://creativecommons.org/licenses/by/4.0/). 